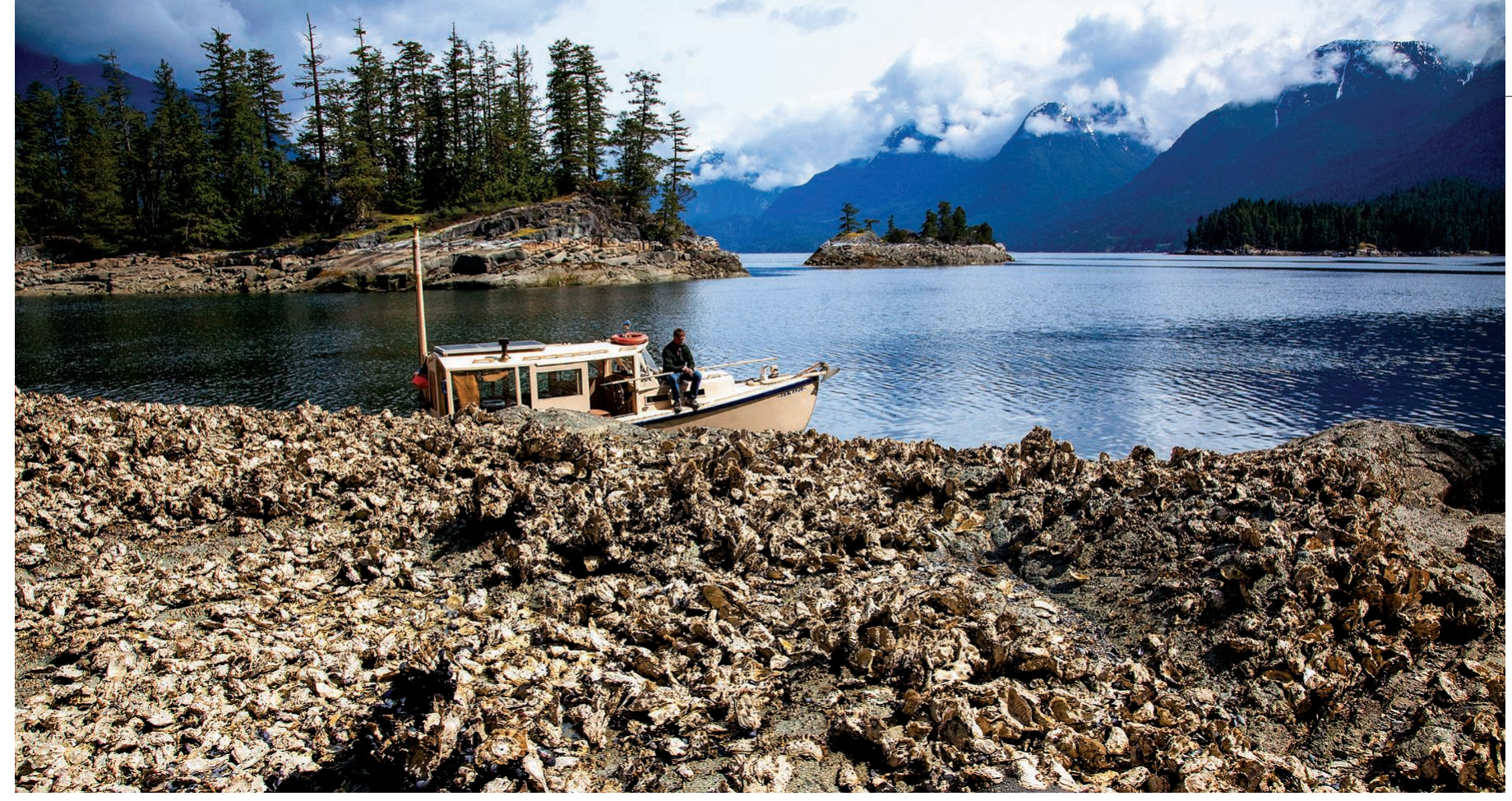

\title{
ECOLOGY
}

\section{Rapid reorganization of global biodiversity}

Marine systems outpace terrestrial habitats in biodiversity erosion

\section{By Britas Klemens Eriksson ${ }^{1}$ and Helmut Hillebrand ${ }^{2,3}$}

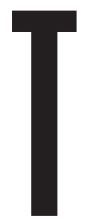

wenty-five years of research on the relationship between biodiversity and ecosystem function have revealed that biodiversity drives fundamental ecosystem processes and regulates their temporal and spatial stability $(1,2)$. Despite clear signs that human efforts have failed to halt global biodiversity loss $(3,4)$, it has been difficult to identify corresponding signs of global-loss trends in the context of local ecosystems (5-9). On page 339 of this issue, Blowes et al. (10) report their analysis of local biodiversity changes using a large dataset of $>50,000$ biodiversity time series from 239 studies. Each time series represents a record of species composition at a selected site over time, with sites representing all major ecosystem types and climatic zones. The authors demonstrate that the identities of species and their abundances are being rapidly reorganized.

Although the proportion of reported global extinctions remains small compared with previous mass extinctions, the current decline in the abundance of myriad species and the elevated danger of their extinction have raised scientific concern over the ill effects of biodiversity loss on human health and well-being (3). The controversy over global versus local changes in biodiversity arose from comprehensive analyses of trends in species numbers worldwide; the data revealed that local communities show strong species turnover but no systematic decrease in the total number of species-a metric referred to as species richness. In fact, most habitats undergo replacement of some or many species by other distinct species with no general shift in the total number of species $(5,6)$. Even coastal time series show a systematic increase in average species richness over time, and declines are observed only in locations with strong human pressures (7).

Together, these studies (5-7) initiated a debate on why the average number of species in local communities has not (yet) been negatively affected by the global erosion of biodiversity $(5-9,11)$. A key lesson learned from this debate is that biodiversity change represents much more than a change in the average number of species.

Species richness in a local habitat reflects the net difference between the num- ber of species immigrating into a habitat and the number becoming extinct over time, and it is not a sensitive measure of biodiversity change $(6,7)$, which also includes shifts in species composition and abundances of individual species types (see the figure). A recent supporting study found that a complete exchange of species composition over time without any change in the number of species (that is, species richness) commonly occurs in nature (11).

The same study challenged the expectation that changes in ecosystem conditions (for better or worse) will be reflected by simple trends in the number of species; in fact, this hypothesis invokes an equilibrium view of biodiversity that might rarely be achieved. A habitat undergoing environmental change can become suitable for new species, but their impact on resident species will take time to manifest (see the figure). Thus, native species are likely to survive for some time before they are excluded (for example, through competition). Ecological systems exposed to continuous environmental change can, therefore, be expected to show a systematic increase in the number of species if the rate of immigration is faster than the rate of extinction (so-called extinction debt) (12). 
The Pacific oyster is native to Pacific Asia but has spread through accidental introductions across the world. Today, it is found on shores in Australia, Europe, New Zealand, and North America.

The need to monitor biodiversity changes by addressing not only species identities but also their abundances is intensified by a traditional problem in the ecological and environmental sciences: Most data from relevant monitoring programs are locked up in governmental programs and institutions and are not openly accessible by scientists and the public. To address this serious deficiency, Dornelas and colleagues developed a community-led open-source database of biodiversity time series called BioTIME, with the aim of promoting robust analyses of changes in global biodiversity (13).

Using BioTIME, Blowes et al. present a dynamic perspective of biodiver- sity changes that will shift the discussion on this topic. They show that the rate of change is highly context-dependent, but they also demonstrate increasing instability of biodiversity, which raises concerns in an era of global change. In particular habitats, the number of species either increased or decreased over time, but when assessing all habitats simultaneously, the authors observed an increase in the average number of species across the globe. The most notable finding by Blowes et al. was that local species assemblages were being rapidly reorganized over time, with nearly a third of all species being replaced by new species every decade; these changes in biodiversity were stronger in marine systems than in terrestrial ones. Their study thus highlights that the global biodiversity crisis, at least for now, is not primarily about decline but, rather, about large-scale reorganization.

\section{Interplay of local and regional diversity alters environment}

Three biodiversity scenarios occur at different times in history: equilibrium scenario (past; no global change in biodiversity), current scenario (moderate global change), and future scenario (both regional and local richness decrease over time). Each symbol and color depicts a distinct species.

Regional biodiversity (past)

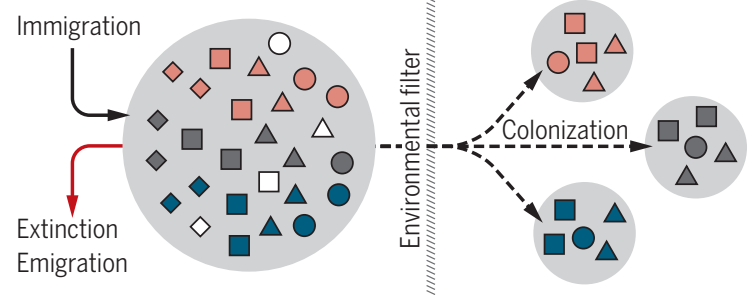

Regional biodiversity (current)

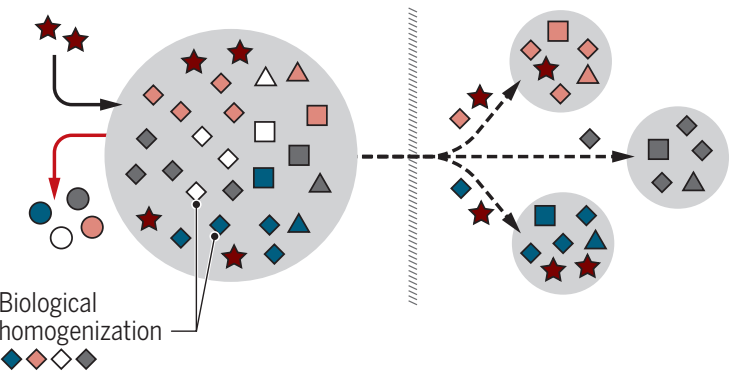

Regional biodiversity (future)

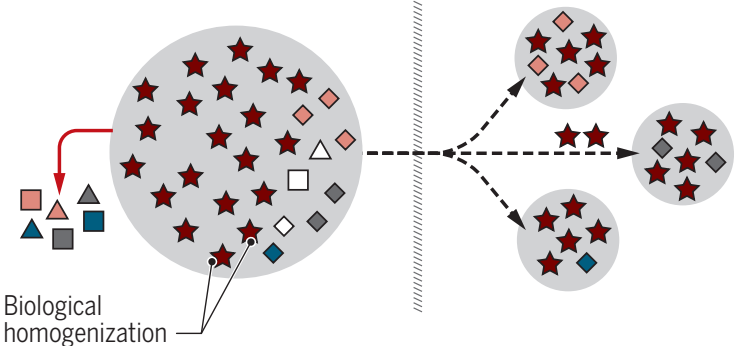

These findings raise questions about species homogenization and adaptability (14), as well as an expectation of precarious ecosystem services in the future, when a large reorganization of local species assemblages affects the temporal stability of ecosystem functions (see the figure). Human-mediated introduction of new species might increase local species richness by elevating immigration rates, but at the same time it promotes biological homogenization-the process by which the composition of species in an ecosystem becomes more uniform. Homogeneity in local species leads to erosion of biodiversity over larger regions (15) and can limit the ability of species communities to adapt to future environmental changes if immigration rates decline (14). Thus, local increases in species richness might even correlate with regional declines in ecosystem resilience over time. Furthermore, by showing high temporal turnover of species composition for all possible trends in species richness, Blowes et al. confirm that such trends are insufficient to describe the consequences of global change for ecological communities.

The study of Blowes et al. also has two implications for ecology as a scientific discipline: It brings together authors who originally had highly divergent views on local biodiversity change, and it demonstrates the importance of open access to biodiversity data of sufficient quality. Only the high quality of BioTIME data enabled Blowes et al. to clearly identify geographical regions that experienced more or less change in biodiversity than expected, which will affect the setting of conservation priorities. With opensource access to international databases, the scientific community can more precisely monitor the biodiversity crisis and develop local solutions.

\section{REFERENCES AND NOTES}

1. F.Pennekamp et al., Nature 563,109 (2018).

2. J. E. Duffy, C. M. Godwin, B. J. Cardinale, Nature 549, 261 (2017).

3. IPBES, "Global assessment report on biodiversity and ecosystem services of the Intergovernmental Science-Policy Platform on Biodiversity and Ecosystem Services" (IPBES Secretariat, 2019).

4. D.P.Tittensor et al., Science 346, 241 (2014).

5. M. Vellend et al., Proc. Natl. Acad. Sci. U.S.A. 110 19456 (2013).

6. M. Dornelas et al., Science 344, 296 (2014)

7. R. Elahiet al.,Curr. Biol. 25,1938 (2015).

8. A. Gonzalez et al., Ecology 97, 1949 (2016).

9. M. Vellend et al.,Ecology 98,583 (2017).

10. S. A. Blowes et al., Science 366,339 (2019).

11. H. Hillebrand et al., J. Appl. Ecol. 55, 169 (2018)

12. S. T. Jackson, D. F. Sax, Trends Ecol. Evol. 25,153 (2010).

13. M. Dornelas et al., Glob. Ecol. Biogeogr. 27,760 (2018).

14. D. Hodapp et al., Ecol. Lett. 21,1364 (2018).

15. T. Finderup Nielsen, K. Sand-Jensen, M. Dornelas, H. H. Bruun, Ecol. Lett. 22, 1650 (2019). 


\section{Science}

\section{Rapid reorganization of global biodiversity}

Britas Klemens Eriksson and Helmut Hillebrand

Science 366 (6463), 308-309.

DOI: $10.1126 /$ science.aaz4520

ARTICLE TOOLS

RELATED

CONTENT

REFERENCES

PERMISSIONS http://science.sciencemag.org/content/366/6463/308

http://science.sciencemag.org/content/sci/366/6463/339.full

This article cites 14 articles, 4 of which you can access for free http://science.sciencemag.org/content/366/6463/308\#BIBL

http://www.sciencemag.org/help/reprints-and-permissions

Science (print ISSN 0036-8075; online ISSN 1095-9203) is published by the American Association for the Advancement of Science, 1200 New York Avenue NW, Washington, DC 20005. The title Science is a registered trademark of AAAS.

Copyright @ 2019 The Authors, some rights reserved; exclusive licensee American Association for the Advancement of Science. No claim to original U.S. Government Works 